\title{
Hydrocarbon oxidation high-temperature chemistry ${ }^{\star}$
}

\author{
Jürgen Warnatz ${ }^{\dagger}$ \\ Interdisciplinary Center of Scientific Computing (IWR), Heidelberg University, Im \\ Neuenheimer Feld 368, D-69120 Heidelberg, Germany
}

\begin{abstract}
The exact knowledge of hydrocarbon oxidation kinetics is very important due to the fact that this process is involved in many technological processes: combustion in engines and furnaces, flame synthesis of materials, partial oxidation processes in chemical technology, catalytic combustion, and exhaust gas treatment, etc. An overview is given on the present state of the art with respect to kinetic data on gas-phase and (shortly) surface oxidation of hydrocarbons. Furthermore, some applications are described in the areas mentioned above. Examples for the importance of the gas-phase oxidation of hydrocarbons are ignition and combustion in engines and furnaces and partial oxidation processes in industrial chemical reactors. In many applications, both gas-phase and surface chemistry are taking place. Examples here are flame generation of diamonds and syngas generation.
\end{abstract}

\section{INTRODUCTION}

It is well known for many decades, that combustion chemistry is a rather complex phenomenon [1,2], and realistic reaction mechanisms for simple hydrocarbons have been published in the last decade [3-5]. Nevertheless, for 2D or 3D applications in combustion science and technology, one-step approaches are used nearly exclusively at the present to make solutions possible within realistic computing times or to avoid principal physical problems (e.g., closure problems in modeling turbulent combustion). In this case, the global chemical reaction can be described in the general form

$$
\sum_{i=1}^{n_{\mathrm{S}}} v_{i}^{(\mathrm{e})} \mathrm{A}_{i} \rightarrow \sum_{i=1}^{n_{\mathrm{S}}} v_{i}^{(\mathrm{p})} \mathrm{A}_{i}
$$

where $\mathrm{A}_{i}$ are species symbols $\left(i=1, \ldots, n_{\mathrm{S}}\right)$ and the $v_{i}$ are stoichiometric numbers (index e for reactants, $\mathrm{p}$ for products). According to the pioneering of Guldberg and Waage [6], the reaction rate $R_{i}$ of species $i$ in eq. 1 often is proportional to powers of molar concentrations $c_{i}$, if the variation of experimental conditions is sufficiently small:

$$
R_{i}=\left(\frac{\mathrm{d} c_{i}}{\mathrm{~d} t}\right)_{\text {chem }}=\kappa \cdot c_{1}^{\alpha_{1}} \cdot c_{2}^{a_{2}} \cdot \ldots \cdot c_{n_{\mathrm{S}}}^{\alpha} n_{\mathrm{S}} .
$$

The advantage of this approach, of course, is its short, simple formulation. However, this is paid for with a huge disadvantage: No extrapolation is possible to other experimental conditions, and even interpolation is dangerous due to the fact that the parameters $\kappa$ (rate coefficient) and $\alpha_{i}$ (reaction order with respect to $c_{i}$ ) in general are empirical parameters dependent on the experimental conditions, and cannot be given a physical meaning in a simple way (which means that no values can be estimated):

$$
\kappa=\kappa\left(T, p, c_{1}, c_{2}, \ldots, c_{n_{\mathrm{S}}}\right) \text { with } \alpha_{i}=\alpha_{i}\left(T, p, c_{1}, c_{2}, \ldots, c_{n_{\mathrm{S}}}\right) \text {. }
$$

\footnotetext{
*Lecture presented at the $10^{\text {th }}$ International Conference on High Temperature Materials Chemistry (HTMC-X), Jülich, Germany, 10-14 April 2000. Other presentations are published in this issue, pp. 2101-2186.

†E-mail: warnatz@iwr.uni-heidelberg.de
} 
A different approach is to use a reaction mechanism consisting of a set of elementary reactions [7]. In contrast to global reactions like the one-step reaction (eq. 1), these (thermal) reactions occur on a molecular level in the same way as the macroscopic reaction equation is written. Thus, $\alpha_{i}$ and $\kappa$ have a well-defined physical meaning: The reaction orders are equal to the (constant) reaction molecularities, and the rate coefficients can be identified, that is, to correspond to molecular vibration frequencies for unimolecular steps or gas kinetic collision numbers for bimolecular steps, thus being a function exclusively of temperature. This means that measurements for the determination of $\alpha_{i}$ and $\kappa$ can be made at experimentally well-accessible conditions and extrapolated to other conditions of pressure and concentrations, and that missing measurements can be replaced by results of quantum mechanics in the near future.

Unfortunately, these sets of elementary reactions can be excessively large (the number $m_{\mathrm{R}}$ of reactions will be up to $\sim 3000$ in the ignition examples presented later, the number $n_{\mathrm{S}}$ of species up to 1000):

$$
\sum_{i=1}^{n_{\mathrm{S}}} v_{i j}{ }^{(\mathrm{e})} \mathrm{A}_{i} \rightarrow \sum_{i=1}^{n_{\mathrm{S}}} v_{i j}{ }^{(\mathrm{p})} \mathrm{A}_{i} ; j=1, \ldots, n_{\mathrm{R}} .
$$

The evaluation of the chemical reaction rates $R_{i}$ is then a very time-consuming procedure (leading to computation times of dozens or hundreds of hours on presently available supercomputers for simple 2D flames [8]):

$$
R_{i}=\left(\frac{\mathrm{d} c_{i}}{\mathrm{~d} t}\right)_{c h e m}=\sum_{j=1}^{n_{\mathrm{R}}} \kappa_{j}\left(v_{i j}^{(\mathrm{p})}-v_{i j}^{(\mathrm{e})}\right) \bigsqcup_{n=1}^{n_{\mathrm{S}}} c_{n}^{v_{n j}^{(\mathrm{e})}} ; i=1, \ldots, n_{\mathrm{S}} .
$$

A further serious complication is stiffness of the differential equation system (eq. 5) due to extremely different time scales acting in such a multi-step mechanism [9], making necessary time-consuming implicit solutions.

\section{THERMODYNAMIC DATA AND TRANSPORT MODELS}

High-temperature hydrocarbon oxidation usually is connected with transport and flow processes. Furthermore, thermodynamic data are needed to calculate specific heat capacities and enthalpies in the energy balance equation and for the computation of reverse reaction rate coefficients in the reaction mechanism (see below).

\section{Thermodynamic data}

For this purpose, polynomial fits of species molar heat capacities $C_{\mathrm{p}, i}$ are used, consisting of seven coefficients for high $(T>1000 \mathrm{~K})$ and for low $(T<1000 \mathrm{~K})$ temperature (in each case, five coefficients for molar heat capacities $C_{\mathrm{p}, i}$, and two integration constants for enthalpy and entropy; details are in refs 10 and 11). A few examples are given in Table 1.

\begin{tabular}{|c|c|c|c|c|c|}
\hline $\mathrm{H} 2 \mathrm{O}$ & $20387 \mathrm{H}$ & & G 0300.00 & 1000.00 & 1 \\
\hline $0.02672145 \mathrm{E}+02$ & $0.03056293 \mathrm{E}-01$ & $-0.08730260 \mathrm{E}-05$ & 0.12009964E-09 & $-0.06391618 \mathrm{E}-13$ & 2 \\
\hline$-0.02989921 E+06$ & $0.06862817 \mathrm{E}+02$ & $0.03386842 \mathrm{E}+02$ & $0.03474982 \mathrm{E}-01$ & $-0.06354696 \mathrm{E}-04$ & 3 \\
\hline $0.06968581 \mathrm{E}-07$ & $-0.02506588 \mathrm{E}-10$ & $-0.03020811 \mathrm{E}+06$ & $0.02590232 \mathrm{E}+02$ & & 4 \\
\hline $\mathrm{HCO}$ & $121286 \mathrm{H}$ & $\mathrm{C} \quad 1 \mathrm{O}$ & G 0300.00 & 1000.00 & 1 \\
\hline $0.03557271 \mathrm{E}+02$ & $0.03345572 \mathrm{E}-01$ & $-0.13350060 \mathrm{E}-05$ & $0.02470572 \mathrm{E}-08$ & $-0.01713850 \mathrm{E}-12$ & 2 \\
\hline $0.03916324 \mathrm{E}+05$ & $0.05552299 \mathrm{E}+02$ & $0.02898329 \mathrm{E}+02$ & $0.06199146 \mathrm{E}-01$ & $-0.09623084 E-04$ & 3 \\
\hline $0.10898249 \mathrm{E}-07$ & $-0.04574885 E-10$ & $0.04159922 \mathrm{E}+05$ & $0.08983614 \mathrm{E}+02$ & & 4 \\
\hline
\end{tabular}

Table 1 Examples for a polynomial representation of thermodynamic data. 


\section{Transport models}

Hydrocarbon oxidation in combustion processes, due to their rapidity, in most cases lead to spatially nonuniform condition, inducing flow and transport processes. Transport takes care of broadening of steep profiles, where the temporal change of the quantity considered (e.g., temperature $T$, mass fractions $w_{i}$, velocity $\left.v, \ldots\right)$ are proportional to the curvature of the actual profile $\left(2^{\text {nd }}\right.$ law of Fourier for $T, 2^{\text {nd }}$ law of Fick for $w_{i}, z$ is the space coordinate). The transport coefficients (i.e., diffusion coefficient $D_{i}$ for $w_{i}$, heat conductivity $\lambda$ for $T$, viscosity $\eta$ for $v, \ldots$ ) can be determined from intermolecular potential properties like the Lennard-Jones parameters $\sigma$ (molecular diameter) and $\varepsilon$ (potential well depth); e.g., for heat transport

$$
\frac{\partial T}{\partial t}=\lambda \frac{\partial^{2} T}{\partial z^{2}} \text { with } \lambda=\frac{25}{32} \cdot \frac{\sqrt{\pi m k T}}{\pi \sigma^{2} \Omega^{(2,2) *}(\varepsilon)} \cdot \frac{c_{V}}{m},
$$

where $m=$ mass of the particle, $\kappa=$ Boltzmann constant, and $c_{V}=c_{V} / N_{\mathrm{A}}=$ molecular heat capacity. The inclusion of real gas effects modifies this rigid sphere result by a factor $\Omega^{(2,2)^{*}}$ (reduced collision integral, depending on $\varepsilon$ ). An exhausting treatment is given in the book by Hirschfelder, Curtiss, and Bird [12]; computer packages for the determination of pure species and mixture transport properties have been described in the literature refs. 13-15.

\section{HYDROCARBON OXIDATION IN COMBUSTION PROCESSES}

Five steps are necessary to develop a working mechanism for the oxidation of hydrocarbons [3]:

1. Collection of all available experimental data on elementary reactions involved in the $\mathrm{H}_{2}-\mathrm{O}_{2}-\mathrm{CO}-\mathrm{C}_{1}-\mathrm{C}_{2}$ system. Compilations of this material are given (e.g., in refs $16-18$ ).

2. Extension of these data to higher hydrocarbons with help of group additivity rules $[19,20]$; see section "Automatic generation of reaction mechanisms".

3. Test of these rate data with the help of experimental results on typical, but simple, (0D, 1D) combustion situations: ignition, flame propagation, flame structure.

4. Modification of rate coefficients within the range of their error limits to reproduce the data on ignition, flame propagation, and flame structure.

5. The most dangerous last step: addition of missing reactions using estimates of rate coefficients.

Some features of the reaction mechanisms resulting from this procedure are discussed in the following.

\section{Fast fuel decomposition by radical pyrolysis}

Calculations for flames in mixtures of hydrocarbons up to $\mathrm{C}_{12} \mathrm{H}_{26}$ with air [3,20] show a very simple result which can be extended to the higher alkanes. In lean and moderately rich flames the hydrocarbon is attacked by $\mathrm{O}, \mathrm{H}$, and $\mathrm{OH}$, in the first step. These radicals are produced by the chain-branching steps of the oxyhydrogen reaction. Afterwards, thermal decomposition to smaller alkyl radicals by fast thermal elimination of alkenes turns out to be the only relevant reaction of the higher alkyl radicals (see Fig. 1a). The three other possible reactions (alkyl radical recombination or disproportionation, alkyl $+\mathrm{O}_{2}$ to form an alkene and $\mathrm{HO}_{2}$ and alkyl $+\mathrm{O}$ to form an aldehyde and $\mathrm{H}$ atoms) are completely unimportant for propyl and the higher alkyl radicals [3].

Thus, the problem of alkane oxidation can be reduced to the oxidation of methyl and ethyl radicals which is relatively well known (see next section). Only the relatively slow thermal decomposition of the smallest alkyl radicals $\left(\mathrm{CH}_{3}\right.$ and $\left.\mathrm{C}_{2} \mathrm{H}_{5}\right)$ competes with recombination/disproportionation and with oxidation reactions by $\mathrm{O}$ atoms and $\mathrm{O}_{2}$. This part of the mechanism is rate-controlling in the combustion of alkanes and alkenes, and is therefore the reason for the similarity of all alkane and alkene flames. 


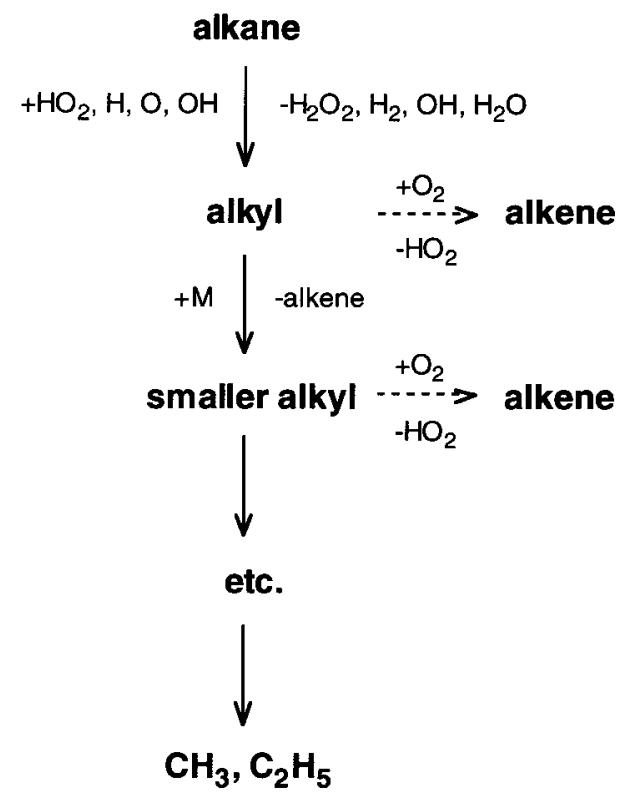

Fig. 1a Alkyl radical decomposition.

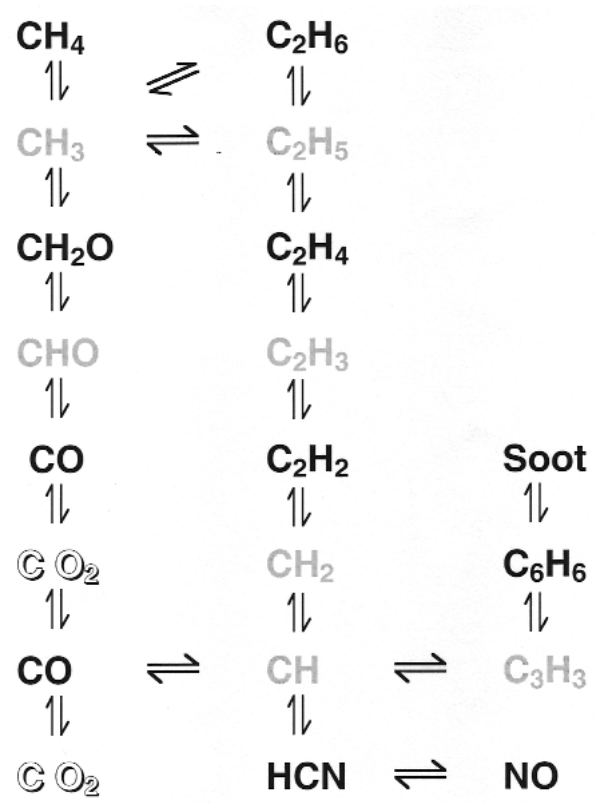

Fig. 1b Oxidation of $\mathrm{C}_{1} / \mathrm{C}_{2}$ hydrocarbons.

\section{Slow oxidation of small hydrocarbon fragments}

The oxidation of $\mathrm{C}_{1^{-}}$and $\mathrm{C}_{2}$-hydrocarbons is now well known from isolated measurements of the relevant elementary reactions and their rate coefficients [16-19]. The flame calculations presented here show methane to be attacked exclusively by $\mathrm{H}, \mathrm{O}$, and $\mathrm{OH}$ (see Fig. 1b). The resulting $\mathrm{CH}_{3}$ radical reacts only with $\mathrm{O}$ atoms to give formaldehyde. The $\mathrm{CHO}$ radical is formed then by $\mathrm{H}$ atom abstraction. $\mathrm{CHO}$ can decompose thermally yielding $\mathrm{CO}$ and $\mathrm{H}$ atoms, or the $\mathrm{H}$ atom can be abstracted by $\mathrm{H}$ or $\mathrm{O}_{2}$.

This simple scheme is complicated by the recombination of $\mathrm{CH}_{3}$. In stoichiometric $\mathrm{CH}_{4}$-air flames, this path consumes about $30 \%$ of the $\mathrm{CH}_{3}$; in rich flames, this recombination ratio increases to about $80 \%$ [21]. In this sense, methane combustion in rich flames is mainly the combustion of $\mathrm{C}_{2}$-hydrocarbons. The recombination of $\mathrm{CH}_{3}$ leads mainly to $\mathrm{C}_{2} \mathrm{H}_{6}$ in a pressure-dependent reaction, but partly to $\mathrm{C}_{2} \mathrm{H}_{5}$ and/or $\mathrm{C}_{2} \mathrm{H}_{4}$ in pressure-independent reactions. $\mathrm{C}_{2} \mathrm{H}_{6}$ again is attacked by $\mathrm{H}, \mathrm{O}$, and $\mathrm{OH}$ to form $\mathrm{C}_{2} \mathrm{H}_{5}$, the consumption of which is relatively complicated due to many competing reactions and due to the pressure dependence of its thermal decomposition (see Fig. 1b).

\section{Flame propagation}

Results on flame front structure and on the velocity of stationarily burning flames into the unburnt gas can be extracted from computations solving the Navier-Stokes equations using the reaction mechanism, the thermodynamics, and the transport model described above, if the coordinate system is moved with the flame front and the calculation is continued until stationarity is reached. The mechanism for the oxidation of hydrocarbons presented above should predict experimental results on flame front structure and flame propagation velocities. In fact, within the limits of experimental error, there is agreement between experiments and calculations for free flame velocities, e.g., in aliphatic hydrocarbon-air systems (see Fig. 2).

More insight into the high-temperature reaction mechanism during flame propagation is provided by a systematic variation of rate coefficients in calculations of the flame velocity of lean, stoichio- 
metric, and rich $\mathrm{C}_{3} \mathrm{H}_{8}$-air flames at atmospheric pressure (see Fig. 3). For the large majority of reactions there is negligible sensitivity (therefore not shown).

It is clearly shown that the flame velocities are relatively insensitive to reactions specific for the fuel oxidation. However, there is a strong influence of the two unspecific reactions of $\mathrm{H}$ atoms with $\mathrm{O}_{2}$ and of $\mathrm{CO}$ with $\mathrm{OH}$ radicals. This means that lean and nearly stoichiometric hydrocarbon flames, on the whole, can be characterized as $\mathrm{H}_{2}-\mathrm{O}_{2}-\mathrm{CO}$ flames fed by the hydrocarbon. Nevertheless, for a detailed description of these flames none of the elementary steps in the reaction mechanism can be neglected.

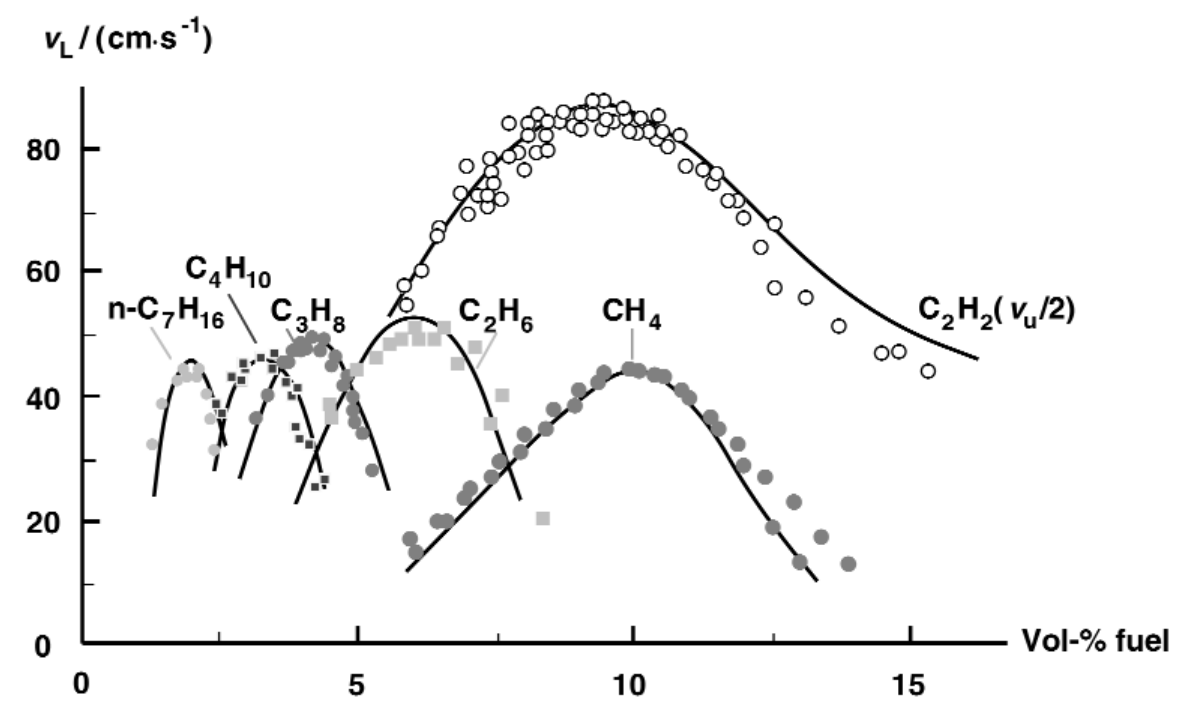

Fig. 2 Flame velocities $v_{\mathrm{u}}$ in hydrocarbon-air mixtures $\left(p=1\right.$ bar, $\left.T_{\mathrm{u}}=298 \mathrm{~K}\right)$ as function of concentration. Points: measurements (see ref. 3), solid line: calculations (see ref. 3).

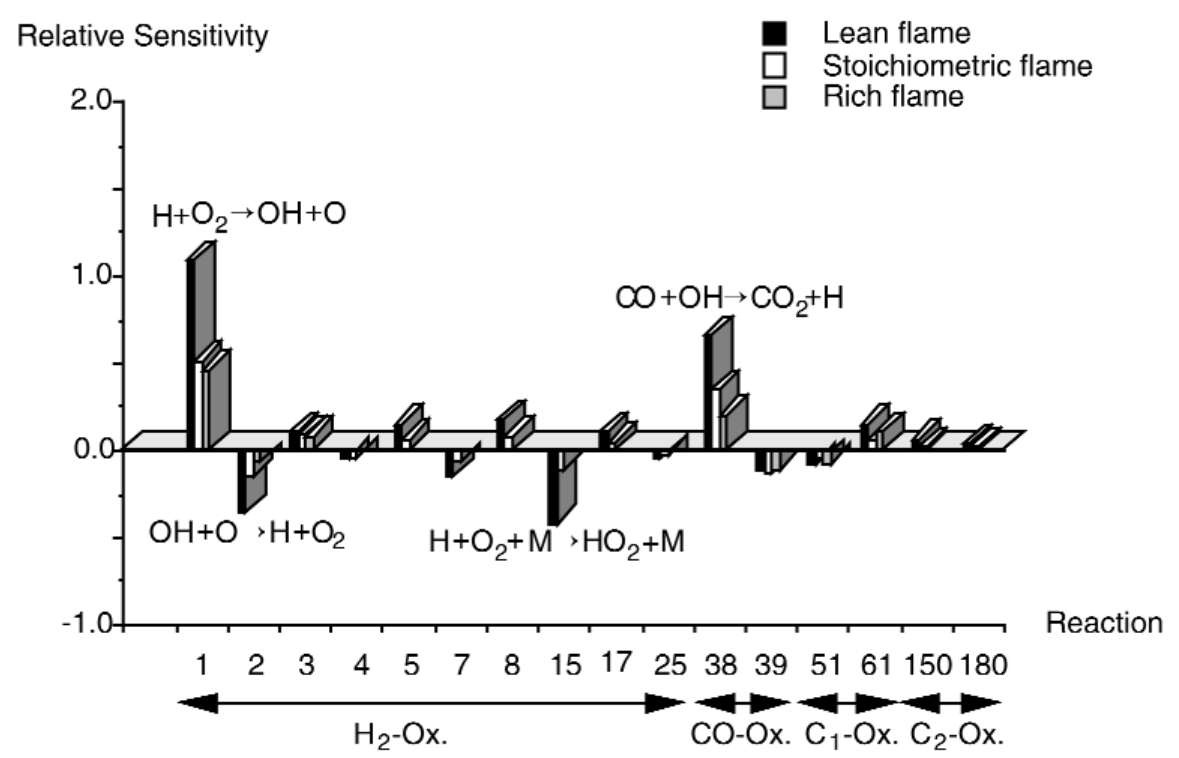

Fig. 3 Sensitivity analysis in $\mathrm{C}_{3} \mathrm{H}_{8}$-air flames $\left(p=1\right.$ bar, $\left.T_{\mathrm{u}}=298 \mathrm{~K}\right)$; see ref. 5 . 


\section{HYDROCARBON OXIDATION IN AUTO-IGNITION PROCESSES}

The understanding of ignition processes is essential, for example, for industrial safety and internal combustion engine design. Ignition mainly is governed by chain-branching processes which are rather relatively unspecific of the fuel considered at high temperature, whereas they are much more fuel specific at low temperature, leading to very complex reaction systems if the different isomeric structures are taken into consideration [5]. Chain branching at high temperature $(T>1100 \mathrm{~K}$ at $p=1$ bar) is predominantly provided by (radicalic species are marked by a point)

$$
\mathrm{H}^{\bullet}+\mathrm{O}_{2} \rightarrow \mathrm{OH}^{\bullet}+\mathrm{O}^{\bullet}
$$

At medium temperature $(1100 \mathrm{~K}>T>900 \mathrm{~K}$ at $p=1 \mathrm{bar})$, additional chain branching is introduced by the following reaction sequence

$$
\begin{aligned}
& \mathrm{HO}_{2}{ }^{\bullet}+\mathrm{RH} \rightarrow \mathrm{H}_{2} \mathrm{O}_{2}+\mathrm{R}^{\bullet} \\
& \mathrm{H}_{2} \mathrm{O}_{2}+\mathrm{M} \rightarrow \mathrm{OH}^{\bullet}+\mathrm{OH}+\mathrm{M}
\end{aligned}
$$

At low temperature ( $<<900 \mathrm{~K}$ at $p=1$ bar), so-called "degenerated chain-branching" is taking place, characterized by the fact that the precursor of chain-branching (here: $\mathrm{RO}_{2}{ }^{\circ}$ ) is decomposed at higher temperature, leading to an inverse temperature dependence of the reaction rate:

$$
\begin{aligned}
& \mathrm{R}^{\bullet}+\mathrm{O}_{2}=\mathrm{RO}_{2} \\
& \mathrm{RO}_{2} \rightarrow \mathrm{R}^{\prime} \mathrm{OOH}^{\bullet} \\
& \mathrm{R}^{\prime} \mathrm{OOH}^{\prime} \rightarrow \mathrm{OH}^{\bullet}+\mathrm{R}^{\prime} \mathrm{O}^{\bullet}
\end{aligned}
$$

Subsequently, to attain sufficient chain branching, a second $\mathrm{O}_{2}$-addition has to take place, in a way similar to the first one:

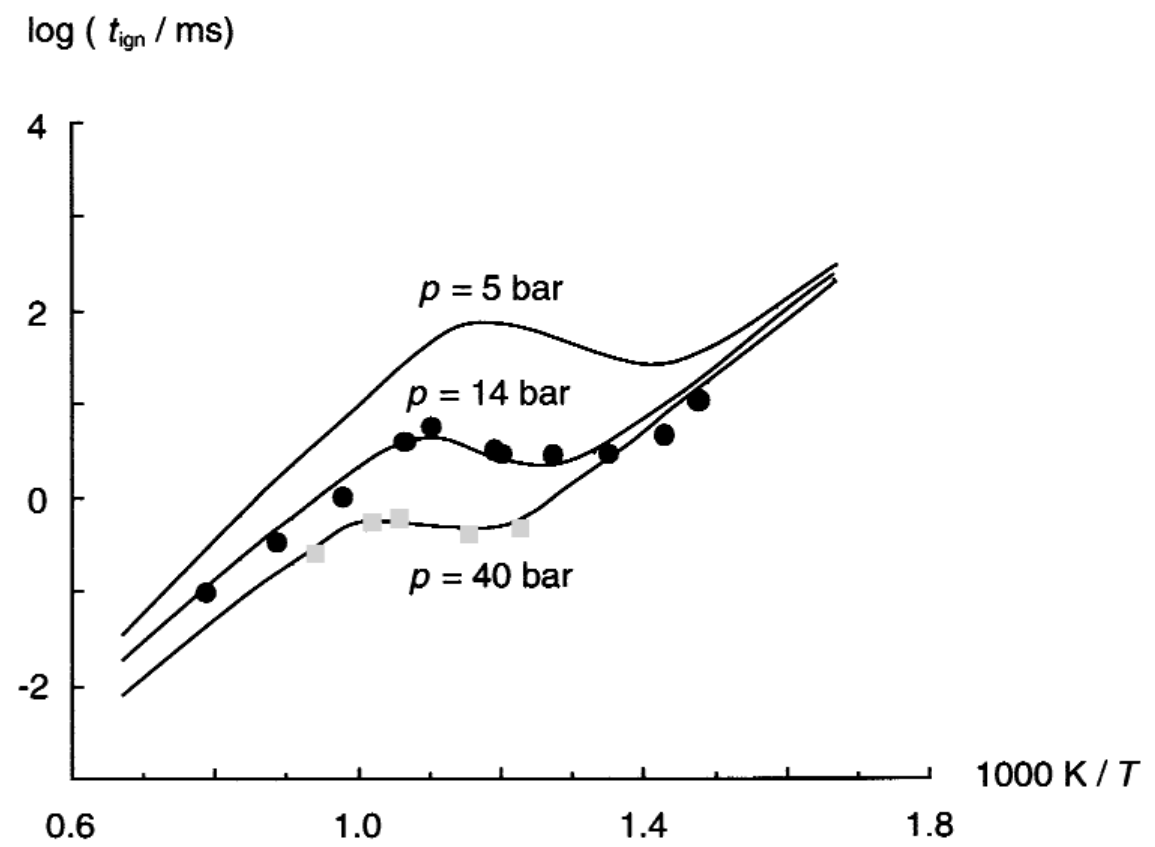

Fig. 4 Ignition delay times in stoichiometric n-heptane-air mixtures; negative temperature coefficients occur just below $1000 \mathrm{~K}$. 


$$
\begin{aligned}
& \mathrm{R}^{\prime} \mathrm{O}_{2} \mathrm{H}^{\bullet}+\mathrm{O}_{2}=\mathrm{O}_{2} \mathrm{R}^{\prime} \mathrm{O}_{2} \mathrm{H}^{\bullet} \\
& \mathrm{O}_{2} \mathrm{R}^{\prime} \mathrm{O}_{2} \mathrm{H}^{\bullet} \rightarrow \mathrm{HO}_{2} \mathrm{R}^{\prime \prime} \mathrm{O}_{2} \mathrm{H}^{\bullet} \\
& \mathrm{HO}_{2} \mathrm{R}^{\prime \prime} \mathrm{O}_{2} \mathrm{H}^{\bullet} \rightarrow \mathrm{HO}_{2} \mathrm{R}^{\prime \prime} \mathrm{O}+\mathrm{OH}^{\bullet} \\
& \mathrm{HO}_{2} \mathrm{R}^{\prime \prime} \mathrm{O} \rightarrow \mathrm{OR}^{\prime \prime} \mathrm{O}^{\bullet}+\mathrm{OH}^{\bullet}
\end{aligned}
$$

A potential reaction competing with the "internal abstraction" of a H atom (R2 and R5) is the elementary step

$$
\mathrm{RO}_{2}^{\bullet}+\mathrm{RH} \rightarrow \mathrm{ROOH}+\mathrm{R}^{\bullet}
$$

which in fact turns out to be relatively unimportant due to its small rate coefficient. By solution of the rate equations of the chemical reaction system considered, ignition delay times can be calculated for several higher hydrocarbons up to cetane $\left(\mathrm{C}_{16} \mathrm{H}_{34}\right)$ and compared to experimental shock tube results. The differences in ignition delay result from the pattern of alkyl radical decomposition that changes from one fuel to another due to the different isomeric structures of the alkyl radicals. Figure 4 shows a comparison between experimental data and the results of corresponding simulations of the ignition delay time $\mathrm{t}_{\text {ind }}$ of $\mathrm{n}-\mathrm{C}_{7} \mathrm{H}_{16}$-air mixtures $[22,23]$.

\section{AUTOMATIC GENERATION AND REDUCTION OF REACTION MECHANISMS}

\section{Automatic generation of reaction mechanisms}

Because of the complexity of low-temperature oxidation, a detailed reaction scheme of higher hydrocarbons (which are components of practical fuels) typically involves several hundred chemical species taking part in thousands of elementary reactions (see Fig. 5). Nevertheless, only a very limited number

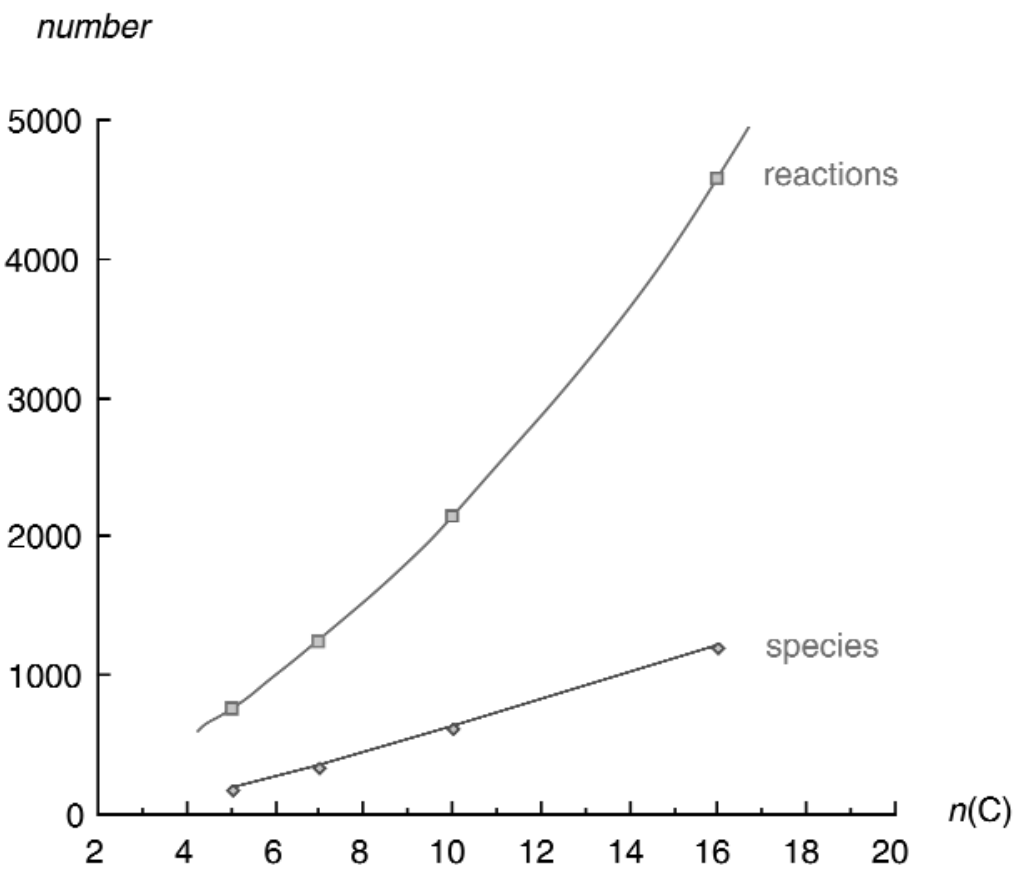

Fig. 5 Number of species and reactions involved in alkane low-temperature oxidation. 
of different reaction types is appearing, e.g., alkane thermal decomposition, H-atom abstraction to form an alkyl radical, alkyl radical isomerization, and $\beta$-decomposition of the alkyl radical for high temperature, and a few additional reaction types at low temperature [22-24]. Therefore, it is possible to formulate these reactions and their rate expressions using simple rules. These rules are executed with the aid of a computer code described in refs. 22-24. LISP is used as a support system, since the best flexibility with regard to the data structures, the algorithm development, and the user interface design is available in this programming language.

\section{Automatic reduction of reaction mechanisms}

A general procedure for simplifying chemical kinetics for complex flow models has been developed recently by Maas and Pope [3,25]. It is based on the dynamical systems approach and decouples fast time-scales. The only input to the procedure are the detailed kinetics mechanism and the number of concentration variables to be used. The governing processes (i.e., flow, molecular transport, and chemical reaction) occur at time-scales which differ by orders of magnitude (chemical reaction time-scales in combustion processes: $10^{-9}$ to $10^{+2}$, physical time-scales: $10^{-5}$ to $10^{-3} \mathrm{~s}$ ). The very fast time-scales in chemical kinetics usually are responsible for equilibration processes (reactions are in partial equilibrium, species are in steady state) and can be decoupled by assuming local equilibrium with respect to the $n^{\mathrm{F}}$ fastest time scales in the system.

Besides reducing the number of equations that have to be solved in complex flow problems, a further advantage of this reduction is that table look-up can be used for the determination of reaction rates that would be impossible for the unreduced system. Furthermore, stiffness is removed from the system, making possible the use of explicit solution methods for the differential equations under consideration. An example is given in Fig. 6 [26].

\section{COMBINED GAS-PHASE AND SURFACE CHEMISTRY}

Catalysis combustion presents a new possibility to reduce NO production. The oxidation here is performed at low temperatures, so that the radical reactions leading to pollutant generation in the gas phase are no more present. Due to problems with the catalyst life-time, often catalytically supported combustion is used, using partly gas-phase combustion (e.g., catalytic combustion in turbines up to $\sim 1000 \mathrm{~K}$, then gas-phase combustion at extremely lean conditions up to the turbine entrance temperature, $\sim 1800 \mathrm{~K}[27])$.
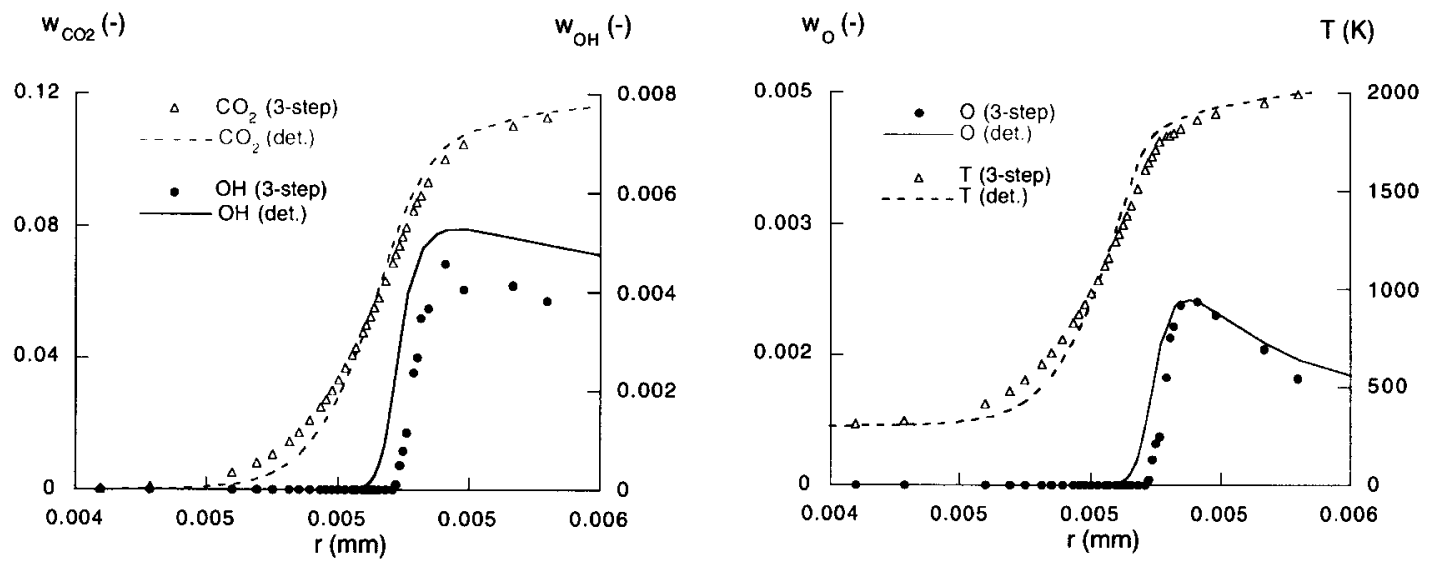

Fig. 6 Concentration profiles in a $\mathrm{CH}_{4}$-air flame with detailed and ILDM-reduced mechanism. 


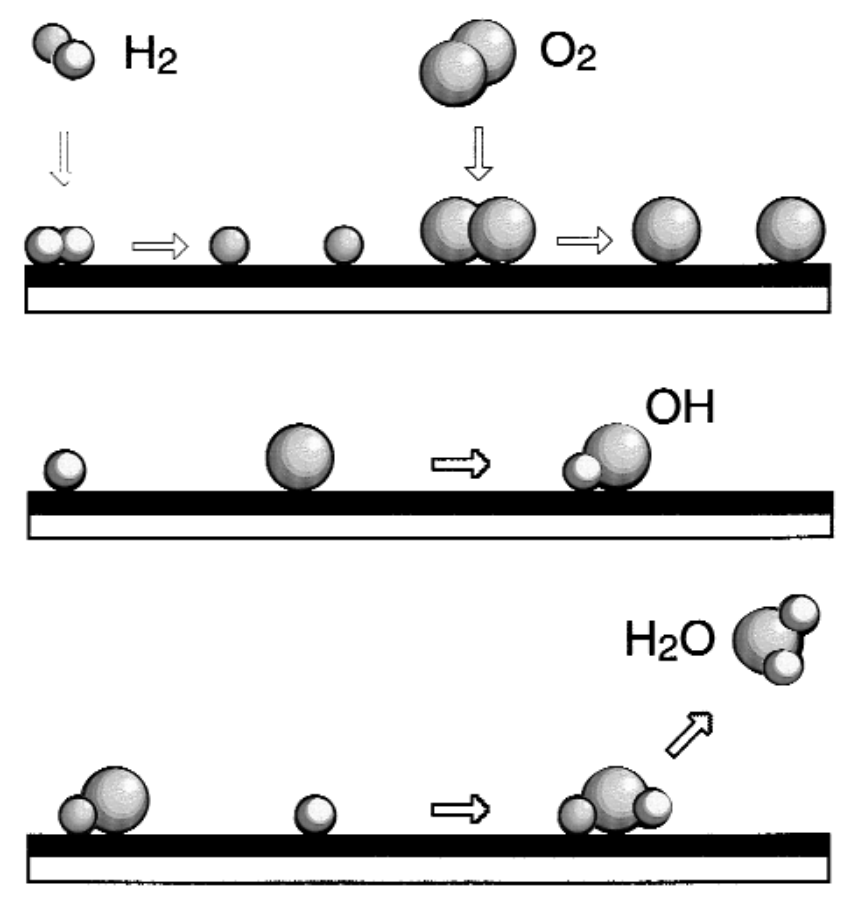

Fig. 7 Langmuir-Hinshelwood reaction mechanism (schematic) for the catalytic oxidation of $\mathrm{H}_{2}$.

Mechanisms for the description of catalytic combustion of simple fuels such as hydrogen and carbon monoxide are described in the literature (see, e.g., ref. 28); a reaction scheme for the oxidation of hydrogen is illustrated by Fig. 7. For the oxidation of methane and propene, attempts exist in the literature to formulate a mechanism [28,29]; the development is not yet finished here.

Other applications for combined gas-phase and surface mechanisms are exhaust gas catalysis [29] and chemical vapor deposition to produce materials such as diamond [30].

\section{REFERENCES}

1. N. Semenov. Chemical Kinetics and Chain Reactions. Oxford University Press, London (1935).

2. W. Jost. Explosions- und Verbrennungsvorgnge in Gasen, Springer, Berlin (1939).

3. J. Warnatz. Proc. Combustion Institute 24, 553 (1992).

4. G. P. Smith, D. M. Golden, M. Frenklach, N. W. Moriarty, B. Eiteneer, M. Goldenberg, C. T. Bowman, R. Hanson, S. Song, W. C. Gardiner, Jr., V. Lissianski, Z. Qin. http://www.me.berkeley.edu/gri_mech/

5. J. Warnatz, U. Maas, R. W. Dibble. Combustion ( $2^{\text {nd }}$ ed.), Springer, Heidelberg (1999).

6. C. M. Guldberg, P. Waage. In Klassiker der exakten Wissenschaften, W. Ostwald (Ed.), Engelmann, Leipzig (1899).

7. M. M. Bodenstein, S. C. Lind. Z. Physik. Chem. 57, 168 (1906).

8. M. Braack. Dissertation, Universität Heidelberg (1998).

9. J. O. Hirschfelder. Proc. Combustion Institute 9, 553 (1963).

10. D. R. Stull, H. Prophet (Eds.). JANAF Thermochemical Tables, U.S. Department of Commerce, Washington DC (1971), and addenda.

11. A. Burcat, Thermochemical Data for Combustion. In Combustion Chemistry, W. C. Gardiner (Ed.), Springer, New York/Heidelberg (1984). 
12. J. O. Hirschfelder, C. F. Curtiss, R. B. Bird. Molecular Theory of Gases and Liquids, Wiley, New York (1964).

13. R. J. Kee, J. Warnatz, J. A. Miller. A Fortran Program Computer Code for the Evaluation of GasPhase Viscosities, Conductivities, and Diffusion Coefficients, SANDIA Report SAND83-8209 (1983).

14. R. J. Kee, G. Dixon-Lewis, J. Warnatz, M. E. Coltrin, J. A. Miller. A Fortran Computer Code for the Evaluation of Gas-Phase Multicomponent Transport Properties. SANDIA Report SAND868246 (1986).

15. P. Paul, J. Warnatz. Proc. Combustion Institute 27, 495 (1998).

16. D. L. Baulch, C. J. Cobos, R. A. Cox, C. Esser, Th. Just, J. A. Kerr, M. J. Pilling, J. Troe, R. W. Walker, J. Warnatz. J. Phys. Chem. Ref. Data 21, 411 (1992).

17. D. L. Baulch, C. J. Cobos, R. A. Cox, C. Esser, Th. Just, J. A. Kerr, M. J. Pilling, J. Troe, R. W. Walker, J. Warnatz. J. Phys. Chem. Ref. Data 23, 847 (1994).

18. D. L. Baulch, C. T. Bowman, C. J. Cobos, R. A. Cox, Th. Just, J. A. Kerr, M. J. Pilling, J. Troe, W. Tsang, R. W. Walker, J. Warnatz. J. Phys. Chem. Ref. Data 23 (2001) submitted for publication.

19. J. Warnatz. "Critical survey of elementary reaction rate coefficients in the C/H/O system", In Combustion Chemistry, W. C. Gardiner Jr. (Ed.), Springer, New York (1984).

20. M. Nehse, J. Warnatz, C. Chevalier. Proc. Combustion Institute 26, 773 (1997).

21. J. Warnatz. In Combustion in Reactive Systems, Progress in Astronautics and Aeronautics, J. R. Bowen, N. Manson, A. K. Oppenheim (Eds.), Vol. 76, AIAA (1981).

22. C. Chevalier, P. Louessard, U. C. Mller, J. Warnatz. Proc. $2^{\text {nd }}$ Int. Symp. on Diagnostics and Modeling of Combustion in Reciprocating Engines, p. 93, The Japanese Society of Mechanical Engineers, Tokyo (1990).

23. K. Fieweger, U. Pfahl, R. Blumental, F. Adomeit. In Kolloquium des Sonderforschungsbereich 224, F. Pischinger Eed.), Motorische Verbrennung, RWTH Aachen (1996).

24. C. Chevalier, J. Warnatz, H. Melenk, Ber. Bunsenges. Phys. Chem. 94, 1362 (1990).

25. U. Maas and S. B. Pope. Comb. Flame 88, 239 (1992).

26. D. Schmidt, J. Segatz, U. Riedel, J. Warnatz, U. Maas. Comb. Sci. Technol. 113, 3 (1996).

27. J. Warnatz. Eurogas '99, Tapir, Trondheim (2001), in press.

28. O. Deutschmann, R. Schmidt, F. Behrendt, J. Warnatz. Proc. Combustion Institute 26, 1747 (1997).

29. J. Braun, T. Hauber, H. Tbben, P. Zacke, D. Chatterjee, O. Deutschmann, J. Warnatz. SAE Technical Paper Series 2000-01-0211 (2000).

30. B. Ruf, F. Behrendt, O. Deutschmann, J. Warnatz. J. Appl. Phys. 79, 7256 (1996). 